\title{
The blood pressure response to foot reflexology adjunct to transcendental meditation training on postmenopausal hypertension
}

\author{
Ghada Ebrahim El Refaye ${ }^{1 *}$ and Hany Farid Eid Morsy Elsisi²
}

*Correspondence: ghada.ibrahim2011@yahoo.com

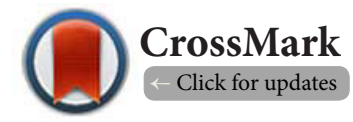

'Department of Physical Therapy for Women's Health, Faculty of Physical Therapy, Cairo University, Egypt.

2Department of Physical Therapy for Internal Medicine, Faculty of Physical Therapy, Cairo University, Egypt.

\begin{abstract}
Background: Hypertension is the most important risk factor that affects the women in the early postmenopausal years. Reflexology is a noninvasive therapy that performed on the hands, feet, or ears at certain reflex points.

Purpose: To detect the response of blood pressure to the foot reflexology and the transcendental meditation training on hypertensive postmenopausal women.

Subjects and Methods: Fifty volunteers, postmenopausal women that had been diagnosed clinically as hypertensive, their age was ranged between (50-65) years, their body mass index (BMI) was $<30 \mathrm{~kg} / \mathrm{m}^{2}$ and their blood pressure was ranged between (140/90) $\mathrm{mmHg}$ and $(180 / 110) \mathrm{mmHg}$. They were randomly assigned into two equal groups in number (A and B). The Participants in the group (A) received the foot reflexology in addition to the transcendental meditation training techniques, while the group (B) received the transcendental meditation training technique only. The treatment program were done three times per week for 8 weeks. Assessment of all subjects in both groups (A and B) were carried out before and after the treatment program throughout using the mercury column sphygmomanometer.
\end{abstract}

Results: Both of the groups (A and B) exhibited a significant reduction $(\mathrm{P}<0.001)$ of their blood pressure values after the end of the two consecutive months of the training program. However, the participants that had been received the foot reflexology plus transcendental meditation training group (A) exhibited a greater reduction in the blood pressure values.

Conclusion: So, it could be concluded that using the foot reflexology in addition to the transcendental meditation training had the superior and the positive effect on hypertensive postmenopausal women than using the transcendental meditation training only.

Keywords: Reflexology, transcendental meditation, menopause, hypertension

\section{Introduction}

Hypertension, is the steady elevation of the blood pressure over $140 / 90 \mathrm{mmHg}$. Hypertension is a common health problem in Egypt with a prevalence rate of $26.3 \%$ among the Egyptian population. Its incidence increases with aging, approximately $50 \%$ of Egyptians over the age of 60 years had been diagnosed as hypertensive [1].

Menopause is a term used to describe the end of the main function of the ovaries: the ripening of ova and the release of the hormones that cause both of the creation of the uterine lining and the subsequent shedding of the uterine lining (the menses or period). It happens in the women in the midlife, amid their late $40 \mathrm{~s}$ or mid $50 \mathrm{~s}$, and signs the end of the fertile phase of the women's [2].

Hypertension is by far the most important risk factor that affects the women in the early postmenopausal years. Around 
30 to half of the women create hypertension before the age of 60 and the onset of hypertension can bring about many side effects that are frequently identified with the menopause [3]. Hypertension is considered as the most popular chronic disease in industrialized countries and represents the most prevalent cardiovascular hazard consider after the fifth decade of life in both the men and the women. The mechanisms that are responsible for the reduction of blood pressure are complex and multifactorial, including the loss of the estrogen, endothelial dysfunction, oxidative stress, the alteration in the renin-angiotensin system overflow and the sympathetic activation [4].

Reflexology is a noninvasive therapy that can be performed on the hands, feet, or ears at specific reflex points. Using of special manipulations with varying degrees of the pressure. It establishes both the psychological and physiological standardization of the body using special manipulations with varying degrees of the pressure $[5,6]$. Reflexology helps in balance all the body organs, physical: by improving the blood circulation, mental: through utilization of the touch and its restorative impact on the body, and helping to relax the body and decrease pain [7]. It enhances the blood supply, lessens fear, disturbance, diminish the sympathetic modulation, increments the vagal adjustment, and decrease the blood pressure in the healthy subjects and patients with coronary artery disease $[\mathbf{8 , 9}$. It has a valuable effect on the quality of life and the well-being, diminishing of the anxiety, the stress and the pain. Additionally, it had been reported that the reflexology has valuable effects on the baroreceptors reflex sensitivity, blood pressure and sinus arrhythmia [10]. Meditation is defined as a stylized mental technique that repetitively practiced for the purpose of obtaining a subjective experience that is commonly described as very relaxed and silent. Meditation has been used in the clinical settings as a method of pain, stress and anxiety relieving $[11,12]$. Transcendental meditation is a particular type of mantra meditation that was designed by Maharishi Mahesh Yogi (1918-2008) in India. The meditation practice includes the utilization of a mantra (specific words such as I am calm) and is practiced for 15-20 minutes twice per day while sitting with one's eyes closed [13]. Transcendental meditation is said to be associated with the clinical outcomes such as the blood pressure reduction and physiological changes such as the reduced of blood cortisol levels [14].

Both of the slow breathing and mental relaxation resulted in the reduction of both the systolic, the diastolic blood pressure, the respiratory rate, the heart rate, and the electromyographic activity with increase in the skin conductance and the peripheral skin temperature [15].

Problematically, the literature review revealed that pharmaceutical treatment of the hypertension, may decrease the symptoms of the high blood pressure, but it does not correct the underlying issue that is causing the problem to begin with. Lifestyle modifications can help to reduce the drug dosage or in some cases, even stop the drug therapy. Non-pharmacologic measures should be a part of the routine management of the hypertension. All the hypertensive drugs have many adverse effects as it can causes dizziness, ankle swelling, headache, fatigue, chest discomfort and cough, so; our study was done to fill the gaps in the understanding of the best way to treat HTN and the prevention and the treatment of hypertension by non-pharmacological intervention [16]. The aim of our study was to detect the effects of both of the foot reflexology and the transcendental meditation training on the hypertensive postmenopausal women. It was hypothesized that the foot reflexology and transcendental meditation training has no effects on hypertensive postmenopausal women.

\section{Subjects and methods Subjects}

Fifty volunteers hypertensive postmenopausal women were referred to us by the gynecologist/ physician at the outpatient clinic of Kasr El Ainy University Hospital, between November 2014 to May 2015, their ages ranged from 50 to 65 years, body mass indexes were all $<30 \mathrm{~kg} / \mathrm{m}^{2}$, and their blood pressure ranged from $140 / 90 \mathrm{mmHg}$ to $180 / 110 \mathrm{mmHg}$. The volunteers had similar daily living activities. The purpose and nature of the study were explained to all participants. All participated women who had the following criteria: They were postmenopausal for at least one year, had essential hypertension (without cause), duration of hypertension (1-3years), the cause of hypertension was limited to behavioral and environmental factors, and were not participated in any pervious exercise training program for at least 3 months prior to the study. All the subjects were asked to avoid using any medical treatments for hypertension during the study period. A detailed medical history was obtained from the all participants to screen for any other pathological conditions, as women with tumor, renal or liver or cardiac disease, cardiopulmonary problems, diabetic, having lesion to higher centers, hypo or hyperthyroidism, had any thrombotic disease of the lower extremities or any foot infections or ulcers, or had undergone foot surgery. The women were randomly distributed into two equal groups ( $A$ and $B$ ) using the computer generated random numbers. Allocation was concealed in sequentially numbered opaque envelopes. Group (A) consisting of twenty five women, performed the foot reflexology in addition to the transcendental meditation training techniques. Group (B) consisting of twenty five women performed the transcendental meditation training technique only. The treatment program was performed three times per week for 2 successive months. The Ethical Committee of the Faculty of Physical Therapy at Cairo University approved this study, No: P.T.REC/012/001116. The study protocol was explained to all of the participating women, who then signed the informed consent form.

\section{Randomization}

The women were randomly assigned to the treatment group 
(A) $(n=25)$ or the control group (B) $(n=25)$ by an independent person who selected numbers from sealed envelopes that containing numbers chosen by a random number generator. The randomization was restricted to permuted blocks of different sizes to ensure that equal numbers were allocated to each group (A) and (B) The sequences assigned to the participants were placed in envelopes containing the allocation to each group A) and (B). An independent person who was blinded to the research protocol and not otherwise involved in the trial operated the random assignment.

\section{Methods}

The assessment of all of the subjects in both groups (A and B) was carried out by the internal medicine physician who was blinded to the purpose of the study. The assessment was done before and after the treatment program through measuring the blood pressure by using the mercury sphygmomanometer. Systolic BP was the point at which the first of 2 or more sounds was heard and the diastolic BP was the point before the disappearance of sounds. Reading of the clinical blood pressure was obtained in the left arm of the sitting patients, after 5 minutes of rest, with using the mercury sphygmomanometer. The timing of BP measurement was the same for all subjects both groups at afternoon.

Before starting the first session, the treatment procedure was carefully explained to the woman, to actively motivate them to perform maximally, also, advice the women to avoid any salty foods and to avoid drinking of coffee, tea and alcohol before the measurement session.

\section{Foot reflexology technique}

All of the subjects in group (A) received foot reflexology by the same physiotherapist who was expertise in the reflexology technique. Each subject was advised to wear comfortable and light clothes and assume the relaxed supine lying position with her feet rested on the plinth in a quiet room.

The patient asked to remove both the socks and shoes in order to receive the treatment program. Inspection for the either feet of the patient for any broken or cuts skin. Then the feet were cleaned carefully with disinfectant wipe. Positioned both of the feet close to each other and imagine the map of the body [17].

\section{Foot reflexology procedures}

Starting with the warming-up through washing the whole of the sole by the warm water. This helps to tones the energy of the whole body, relaxes, and prepares the feet to be practiced on. Then, massaging the foot included the mixture of 5 minutes of the light pressure and light stroking using the whole hand to the dorsal and plantar surfaces for each foot to relax it and also, relax the patient.

Reflexology intervention was applied by using the mixture of thumb walking and finger pivot techniques to the base of the toes and the foot that correspond with the reflex zones.
The pressure was done gently on certain zones with a special concentration on the following points:

(1) Solar plexus point: it is located just below the ball of both feet, at the midline. This point connects to the entire nervous system and can stimulate a profound relaxation effect as well as, minimizes both of stress and anxiety, The solar plexus is highly affected by stress so releasing this reflex point has been known to decrease stress levels as well as increase the body's tolerance for stress.

(2) Pituitary reflex point: it represents the pituitary gland, it is located exactly in the planter aspect of the center of hallux (big toe) of both feet. It was known as the master gland as it regulates the entire endocrine system. Because the pituitary gland harmonizes any imbalances within the body, this reflex point will effectively relax and or energize the body based on what is needed at that moment. It helps to hold this point before bedtime as it will help to calm and relax the body, producing a better night's sleep. Holding this point first thing in the morning will have the opposite effect of energizing the body.

(3) Heart reflex point: it is located on the bottom of the big toe of the planter aspect of both feet. This point improves the regulation of the heart and make the heart pump more efficiently, also, improves the physiological and spiritual health.

(4) Liver reflex point: it is located between the bottom of the ball of the foot and the middle of the right foot. This point is one of the most beneficial acupressure points for promoting the detoxification of the liver as it promotes the blood circulation. The liver has several important functions, including combating infections in the body, clearing the blood of particles and infections including bacteria and neutralizing and destroying drugs and toxins. Giving the liver a boost will help to detoxify the body. Over the festive season, the digestive system will have had a lot of work to do and so may be quite sluggish right now. Reflexology can help with removal of waste and improve the action of the digestive system by increasing blood circulation. Working the liver reflex, by the way, also works the gall bladder reflex which will stimulate the gall bladder to release bile, an important fluid required in digestion and is also a very mild laxative.

(5) Adrenal reflex point: it is located at the base of the second and third metatarsal bones of both feet (The metatarsal bones are the long bones from the toes to the arch, the first metatarsal bone being the long bone connecting to the big toe, the second one next to the big toe). The adrenal cortex produces hormones that regulate levels of fluids and electrolytes.

(6) Kidney reflex point: it is located on the middle of the arch of both feet close to the base of the $2^{\text {nd }}$ metatarsals. The Kidney point is one of the most important points to massage for hypertension. That's because it helps to boost the Kidney Qi, harmonize the Kidney meridian, and tonify kidney deficiencies that may be at the root of elevated blood pressure. As well, those suffering from secondary hypertension related to the kidneys will also benefit from this point. Harmonizing 
the Kidney meridian helps to support kidney function [18].

Foot reflexology sessions were done for 30 minutes (each foot 15 minutes) twice a week for 8 weeks.

\section{Transcendental meditation training technique}

All of the subjects in both groups ( $A$ and $B$ ) received transcendental meditation training by the same physiotherapist expertise in the meditation technique.

Prior to the start of the technique each woman was advised to evacuate her rectum and bladder, to be more relaxed and to wear light and comfortable clothes. The session was done in a quite warm room.

Every subject was assuming the comfortable half lying position with the back well supported, with both arms are relaxed at the sides. Using small cushions and soft pillows to accommodate and support her body curves and then subject was asked to listen and observe to her own regular breathing (in, out and pause in between them) in order to obtain the mental relaxation for 5 minutes. Then, begin to imagine an object in her mind. This object should be pleasurable and simple to her. It could be the moon, the sea, the sky or etc. Some people prefer a favorite sounds, such as slow music. Whichever you choose, try to visualize the word object, or something to represent the sound [20]. Then the woman was asked gently to close her eyes and then, take a deep breath from her nose slowly and make her abdomen like a balloon and then, to count of four, then asked to expire the air from her mouth with a sigh.

This procedure was repeated four times of deep breaths to a count of four and expired to a count of four.

Then repeated four times the pattern of deep breath, and expired to a count of four each, brought her breaths down to a calm and rhythmic pattern.

She took herself through the imagination in somewhere she felt more relaxed as in the river or in the beach in the summer, where she sit and hear the soothing sound of the running water, and watch the beautiful scene, and smell the fresh breath of air [13].

Then the woman would give herself affirmations such as: I am calm, I love to do my tasks in a calm and relaxed manner. This procedure was then repeated for 20 minutes. Transcendental meditation technique was repeated three times a week for 8 weeks. Every subject was advised to repeat the previous techniques daily as the home routine.

\section{Sample size determination}

Based on previous study (Park and Cho., 2004) [21], sample size was calculated according to the difference in blood pressure using Effects of foot reflexology on essential hypertension patients with an effect size of 0.74 . Assuming $\alpha=0.05$, power of $80 \%$, so a sample size of 25 patients per group would be required (GPower 301 http:www.psycho.uni-duesseldorf.de).

\section{Statistical analysis}

The collected data were statistically analyzed using an unpaired $t$ test to compare between the mean values of different variables between the two groups ( $A$ and $B$ ). Paired t test were used to compare variables within the same group. The Statistical Package for the Social Sciences (SPSS) computer program (windows version 16) was used for the data analysis. Data were represented as the means and the standard deviations and the percentage of change were calculated. It was considered to be significant at $P$ value $<0.05$.

To analyze the intra- and interrater agreement, two measures were used the Standard Error of Measurement (SEM) and the Minimum Detectable Change (MDC). The SEM reflects the instrument error and was calculated by dividing the standard deviation (SD) of the mean difference by the square root of 2 (SD of the differences $/ \sqrt{ } 2$ ). The MDC is the minimum change of the measurement that can be interpreted as real change and was calculated using the formula MDC $=1.96 \times \sqrt{ } 2 \times \mathrm{SEM}$ [22].

\section{Results}

A diagram of the participant's retention and randomization throughout the study is shown in Figure 2. A total of 64 participants were initially screened. After the screening process, 50 participants were found to be eligible to participate in the study. In total, 50 (100\%) participants completed the treatment program, and 50 completed the entire study. The general characteristics for all subjects in both ( $A$ and $B$ ) at entry of the study are shown in Table 1 . The results are summarized and presented as the means (SDs) in Tables 2-5.

Table 1. General characteristics for the two studied groups $(A, B)$.

\begin{tabular}{lllll}
\hline Variable & $\begin{array}{l}\text { Group (A) } \\
(\mathbf{n = 2 5})\end{array}$ & $\begin{array}{l}\text { Group (B) } \\
(\mathbf{n}=\mathbf{2 5})\end{array}$ & t-value & P-value \\
\hline Age $(\mathrm{yrs})$. & $53.45 \pm 3.24$ & $54.50 \pm 3.36$ & -1.006 & $0.321(\mathrm{NS})$ \\
Weight $(\mathrm{kg})$ & $79.80 \pm 5.45$ & $80.90 \pm 6.66$ & -0.571 & $0.571(\mathrm{NS})$ \\
Height $(\mathrm{cm})$ & $166.35 \pm 3.94$ & $168.25 \pm 5.50$ & -1.257 & $0.216(\mathrm{NS})$ \\
BMI $\left(\mathrm{Kg} / \mathrm{m}^{2}\right)$ & $28.70 \pm 0.94$ & $28.33 \pm 1.03$ & 1.188 & $0.242(\mathrm{NS})$ \\
\hline
\end{tabular}

Data are expressed as mean \pm SD. NS $=\mathrm{p}>0.05=$ not significant.

Table 2. Comparison between mean values of DBP measured pre- and post-treatment in the two studied groups (A, B).

\begin{tabular}{lll}
\hline & $\begin{array}{l}\text { Study group(A) } \\
(\mathbf{n = 2 5})\end{array}$ & $\begin{array}{l}\text { Control group(B) } \\
(\mathbf{n = 2 5})\end{array}$ \\
\hline Pre-treatment & $98.50 \pm 8.13$ & $99.25 \pm 7.66$ \\
Post-treatment & $86.00 \pm 6.81$ & $95.75 \pm 7.66$ \\
Mean Difference & 12.5 & 3.50 \\
Percentage of improvement & 12.69 & 3.53 \\
t-value & 8.238 & 4.273 \\
P-value & $0.001^{* *}$ & $0.001^{* *}$ \\
\hline
\end{tabular}

Data are expressed as mean \pm SD. $\mathrm{P}<0.01=$ significant.

Comparison between the diastolic blood pressure (DBP) before and after treatment for both groups ( $A$ and $B$ ) by using paired 
Table 3. Comparison between mean values of SBP measured preand post-treatment in the two studied groups $(\mathrm{A}, \mathrm{B})$.

\begin{tabular}{lll}
\hline & $\begin{array}{l}\text { Study group(A) } \\
(\mathbf{n = 2 5 )}\end{array}$ & $\begin{array}{l}\text { Control group(B) } \\
(\mathbf{n = 2 5})\end{array}$ \\
\hline Pre-treatment & $165.75 \pm 14.07$ & $160.75 \pm 12.70$ \\
Post-treatment & $150.50 \pm 11.69$ & $154.0 \pm 12.94$ \\
Mean Difference & 15.25 & 6.75 \\
Percentage of improvement & 9.20 & 4.2 \\
t-value & 8.677 & 6.110 \\
P-value & $0.001^{\star *}$ & $0.001^{\star *}$ \\
\hline
\end{tabular}

Data are expressed as mean \pm SD. $\mathrm{P}<0.01=$ significant.

Table 4. Comparison between mean values of pre-treatment and difference in DBP in the two studied groups $(A, B)$. Study group Control group t-value P-value (A) $(\mathbf{n}=25) \quad$ (B) $(\mathbf{n}=25)$

\begin{tabular}{lllll}
\multicolumn{1}{c}{$(\mathrm{A})(\mathbf{n}=\mathbf{2 5})$} & $(\mathbf{B})(\mathbf{n}=\mathbf{2 5})$ & & \\
\hline $\begin{array}{l}\text { Pre- } \\
\text { treatment }\end{array}$ & $98.50 \pm 8.13$ & $99.25 \pm 7.66$ & -0.300 & $0.766(\mathrm{NS})$ \\
\hline $\begin{array}{l}\text { Mean } \\
\text { difference }\end{array}$ & $12.50 \pm 6.79$ & $3.50 \pm 3.66$ & 5.219 & $0.001^{* *}$ \\
\hline
\end{tabular}

Data are expressed as mean \pm SD. NS $=\mathrm{p}>0.05=$ not significant; $\mathrm{p}<0.01=$ highly significant.

Table 5. Comparison between mean values of pre-treatment and difference in SBP in the two studied groups $(\mathrm{A}, \mathrm{B})$.

\begin{tabular}{lllll}
\hline & $\begin{array}{l}\text { Study group } \\
(\mathrm{A})(\mathbf{n}=\mathbf{2 5})\end{array}$ & $\begin{array}{l}\text { Control group } \\
(\mathbf{B})(\mathbf{n}=\mathbf{2 5})\end{array}$ & t-value & P-value \\
\hline $\begin{array}{l}\text { Pre- } \\
\text { treatment }\end{array}$ & $165.75 \pm 14.07$ & $160.75 \pm 12.70$ & 1.180 & $0.245(\mathrm{NS})$ \\
\hline $\begin{array}{l}\text { Mean } \\
\text { difference }\end{array}$ & $15.25 \pm 7.86$ & $6.75 \pm 4.94$ & 4.095 & $0.001^{\star *}$ \\
\hline
\end{tabular}

Data are expressed as mean \pm SD. NS $=\mathrm{p}>0.05=$ not significant; $\mathrm{p}<0.01=$ significant.

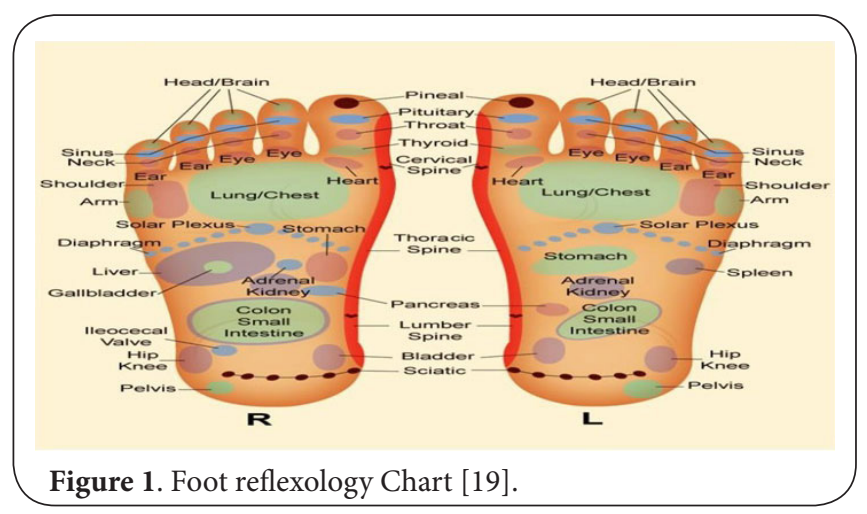

t-test between showed statistically significant decrease $(\mathrm{P}=0.001)$ in diastolic blood pressure as shown in (Table 2).

Comparison between mean values of systolic blood pressure (SBP) measured before and after treatment for both groups ( $A$ and $B$ ) (within group comparison) by using paired t-test between showed statistically significant decrease $(P=0.001)$ in systolic

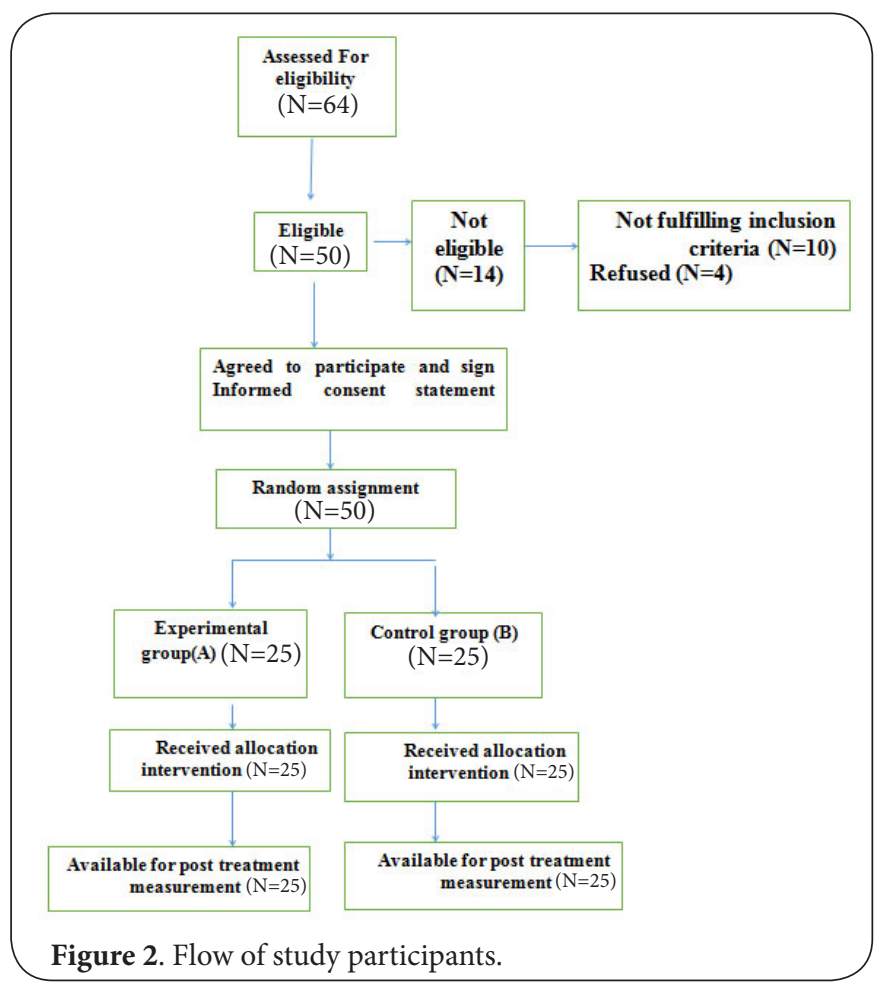

blood pressure in both groups ( $A$ and $B$ ) as shown in (Table 3). Comparison between mean values of DBP before treatment in the two studied groups $(A, B)$ measured by using unpaired $t$ test. There was a statistical highly significant increase in the mean value of difference in DBP in study group (A) when compared with its corresponding value in control group (B) $p$ value $=0.001$ (Table 4).

Comparison between mean values of SBP before treatment in the two studied groups $(A, B)$ measured by using unpaired $t$ test, there was a statistical significant increase in the mean value of difference in SBP in study group (A) compared with its corresponding value in control group (B) $p$ value $=0.001$ (Table 5).

Statistical analysis revealed that, after 8 weeks of the training program, both of the groups (A and $B$ ) exhibited a significant reduction $(P<0.001)$ of their blood pressure values, unpaired t test analysis revealed, the participants that had been received the foot reflexology plus transcendental meditation training group (A) exhibited a greater reduction in the blood pressure values.

With regard to the intra- and interrater agreement assessed using the SEM and MDC, a small SEM was obtained, and therefore, it is expected that the measurements made in the same individual at different times would have a variation of $1.27 \mathrm{mmHg}$, which is related to the measurement error and not to changes in the clinical status of the patient. The MDC values found indicate that a change $>5.30 \mathrm{mmHg}$ has a $<5 \%$ probability of occurring due to random variation or a random error in the measurement. 


\section{Discussion}

Hypertension is a standout among the most widely recognized intense factors to atherosclerotic cardiovascular disease. Hypertension impacts a more noteworthy number of men than women until 55 years of age, however after age 55, the rate of women is higher. Estrogen lack has been connected to the fast increment in the cardiovascular infection in the women who have experienced regular or surgical menopause. Cardiovascular disease is the main source of death in women and kills more than a large portion of a million women each year [23]. The purpose of our study was to detect the effect foot reflexology and transcendental meditation training on hypertensive postmenopausal women. These results of the present study revealed that integrating of the foot reflexology to the transcendental meditation training (group A) produced a significant reduction of their blood pressure values compared to transcendental meditation training alone (group B) after 2 months of the treatment, which indicated that performing the foot reflexology with the transcendental meditation training are more effective on reducing of the blood pressure in postmenopausal women than transcendental meditation training alone.

Our outcomes are in agreement with those of in the investigation of Lu et al., [9] who directed a study to explore the impact of the foot reflexology on the autonomic nervous modulation in with coronary artery disease patients by utilizing of the heart rate variability analysis. They found that foot reflexology may be utilized as an efficient adjunct to the therapeutic regimen to decrement blood pressure and increment the vagal modulation in both healthy people and coronary artery disease patients. Also, the results of this study came in accordance with Park and Cho [21] as they examined the impacts of 6-weeks of using the foot reflexology on fatigue and the blood pressure in 34 elderly, hypertensive patients. They construed that utilizing of foot reflexology brings about a basic decreasing in fatigue, both diastolic and systolic blood pressure, and triglyceride level in the patients.

Kaur et al., [24]. exhibited that the reflexology and foot massage result in noteworthy decline in the heart rate, in both of the systolic and diastolic blood pressure, and amelioration in the oxygen saturation in critically ill patients. Recent researches has moreover shown that adjustments in the luminosity of the skin and the dermal layer structures at a particular reflex points on the feet may offer rise to the changes felt by therapists during the treatment [17].

Reflexology quiets strain and anxiety by promoting vasodilatation, relaxation, reducing of blood pressure, provision of oxygen-rich supplements to the body cells and enhanced the blood flow $[\mathbf{8}, \mathbf{2 5}]$. Regarding group $(A)$ utilizing of the foot reflexology in integration to transcendental meditation training is more effective than utilizing of the transcendental meditation training only in group (B) as many benefits of reflexology may be established by balance of the autonomic nervous system (ANS). The ANS controls the body frameworks that are under unconscious control as heart rate, breathing, and blood pressure. These parameters are very delicate to the stressors and fluctuate according to the psychological or physical alterations that experienced by an individual, though the vagal modulation that controls restful and calming alterations and sympathetic modulation or conventional functioning, that are responsible for regulating the arousal and the "fight or flight" reaction [18]. Furthermore, through impact of the foot reflexology on the baroreceptor reflex, which regulates the blood pressure. It was inferred that foot reflexology basically cut down the baroreceptor reflex affectability, baroreceptor reflex affectability was measured using sinus arrhythmia and stage IV of the valsalva maneuver, the period in the valsalva maneuver during which the blood pressure is substantially elevated over the standard [10]. With the way that skeletal muscles profound relaxation would evoke the relaxation reaction as it was proved that the release of strain in the skeletal musculature had the impact of quieting the mind. The impact of sympathetic activity was counteracted by the relaxation reaction by permitting the activity of parasympathetic nervous system, subsequently exploiting the reciprocal nature of the two components of the autonomic nervous system [26]. This outcome were affirmed by that of Sivasankaran et al. [27] who directed a study to inspect the impact of meditation and yoga on laboratory and hemodynamic parameters, and found significant reduction in the blood pressure (Bp). Also, the results of this study in accordance with those of Schneider et al., [28] they concentrated the impact of 20 minutes twice every day of using the transcendental meditation technique on 201 participants, they concluded that, transcendental meditation group has a valuable effect on lessening of myocardial infarction, the mortality danger, and stroke in coronary heart disease patients than the control group. These changes were associated with lessening of psychosocial stress factors, and blood pressure. Therefore, this practice may be clinically valuable in the secondary prevention of cardiovascular disease. Moreover, Nidich et al., [29] they found that, following 3 months of practicing the transcendental meditation (TM program), there were diminished of the psychological distress and systolic and diastolic blood pressure in the examined group compared with the control group. The results of this study are fortified by Kaushika et al., [15] who reported that, both mental relaxation and slow breathing exercises brought about a fall in the heart rate, systolic blood pressure, diastolic blood pressure, respiratory rate and the electromyographic activity with increase in skin conductance and the peripheral skin temperature. Both the modalities (mental relaxation and slow breathing exercises) expand the parasympathetic tone however have impacts of different intensity on different autonomic parameters.

Slow breathing decreases blood pressure through enhancing of baroreflex sensitivity in hypertensive patients. These impacts show up conceivably useful in the hypertension management [30]. On the other hand, the results of this study 
disagreed with those of Cramer et al. [31] who studied the strength of recommendation and the quality of evidence of yoga program (as a modality of relaxation techniques) continued for 8 weeks as a therapeutic means in the management of the prehypertensive and hypertensive patients, they reported that, no evidence was found for effects of yoga (as a modality of relaxation techniques) on diastolic or systolic blood pressure. Larger studies are needed to confirm the emerging but low-quality evidence that yoga may be a useful adjunct intervention in the management of hypertensive patients. Also, the results of this study contradicting those of Parati et al., [32] who researched the impact of transcendental meditation on blood pressure, their finding did not appear to provide a final answer as to whether (TM) can be considered as an effective non-pharmacological approach for blood pressure reduction in hypertensive subjects. So, they revealed that, there is no sufficient good quality evidence to firmly establish whether or not transcendental meditation (TM) has a positive effect on blood pressure. Future researches, are recommended to determine the differences in outcomes between using medical treatment and reflexology treatment for hypertension in postmenopausal women, also using hand reflexology versus the foot reflexology in treating such cases.

\section{Study limitations}

Our analysis has potential limitations, each of which indicates directions for future study. The primary limitation was the difference between the individual participants, also the psychological status of the women during the treatment period. Every effort was made to overcome these limitations by including the participants with the same socioeconomic standard (House wives with middle level of education). Within these limitations, the unique contribution of our study is that it evaluated the response of blood pressure to foot reflexology and transcendental meditation training on hypertensive postmenopausal women, have not previously been reported. We believe that the results of this study should be used to introduce new guidelines for the treatment of postmenopausal hypertension.

\section{Conclusion}

Finally, it could be concluded that integrating foot reflexology to transcendental meditation training was found to be an effective, safe, cheap and successful adjunct treatment method in reducing hypertension in postmenopausal women.

\section{Competing interests}

The authors declare that they have no competing interests.

\section{Acknowledgment}

Many thanks to all the subjects who participated in this study for their cooperation.

Authors' contributions
\begin{tabular}{|l|c|c|}
\hline Authors' contributions & GER & KFEH \\
\hline Research concept and design & $\checkmark$ & -- \\
\hline Collection and/or assembly of data & -- & $\checkmark$ \\
\hline Data analysis and interpretation & $\checkmark$ & -- \\
\hline Writing the article & $\checkmark$ & -- \\
\hline Critical revision of the article & -- & $\checkmark$ \\
\hline Final approval of article & -- & $\checkmark$ \\
\hline Statistical analysis & $\checkmark$ & -- \\
\hline
\end{tabular}

\section{Publication history}

Editor: Gordon John Alderink, Grand Valley State University, USA. Received: 05-May-2017 Final Revised: 23-Jun-2017

Accepted: 20-Jul-2017 Published: 01-Aug-2017

\section{References}

1. Chobanian AV, Bakris GL, Black HR, Cushman WC, Green LA, Izzo JL, Jr., Jones DW, Materson BJ, Oparil S, Wright JT, Jr. and Roccella EJ. Seventh report of the Joint National Committee on Prevention, Detection, Evaluation, and Treatment of High Blood Pressure. Hypertension. 2003; 42:1206-1252. | Article | PubMed

2. Walker ML and Herndon JG. Menopause in nonhuman primates? Biol Reprod. 2008; 79:398-406. | Article | PubMed Abstract | PubMed FullText

3. Wassertheil-Smoller S, Anderson G, Psaty BM, Black HR, Manson J, Wong N, Francis J, Grimm R, Kotchen T, Langer R and Lasser N. Hypertension and its treatment in postmenopausal women: baseline data from the Women's Health Initiative. Hypertension. 2000; 36:780-789. | Article | PubMed

4. Leuzzi $C$ and Modena MG. Hypertension in postmenopausal women: pathophysiology and treatment. High Blood Press Cardiovasc Prev. 2011; 18:8-13. | Article | PubMed

5. Cressy S. Reflexology. 1st ed. Heinemann educational publisher. U.K. Italy. 2003; 2-4.

6. Jones S. Simply Reflexology. $\mathbf{1}^{\text {st }}$ ed. Sterling Publishing Company Inc. New York. 2009; 9-11.

7. Tiran $P$ and Mackereth A. Clinical Reflexology: A Guide for Integrated Practice. $1^{\text {st }}$ ed. Churchill Livingstone Elsevier, Edinburgh, Scotland. 2011; 50-54.

8. Byers DC. Better health with foot reflexology. $10^{\text {th }}$ ed. Ingham Publishing Inc. Florida. 2001; 275-278.

9. Lu WA, Chen GY and Kuo CD. Foot reflexology can increase vagal modulation, decrease sympathetic modulation, and lower blood pressure in healthy subjects and patients with coronary artery disease. Altern Ther Health Med. 2011; 17:8-14). I PubMed

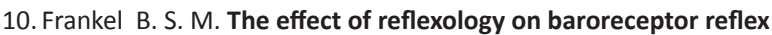
sensitivity, blood pressure and sinus arrhythmia. Complementary Therapies in Medicine. $1^{\text {st }}$ ed. Churchill. London. 1997; 80-84.

11. Davidson RJ, Kabat-Zinn J, Schumacher J, Rosenkranz M, Muller D, Santorelli SF, Urbanowski F, Harrington A, Bonus K and Sheridan JF. Alterations in brain and immune function produced by mindfulness meditation. Psychosom Med. 2003; 65:564-570. | Article I PubMed

12. Cahn BR and Polich J. Meditation states and traits: EEG, ERP, and neuroimaging studies. Psychol Bull. 2006; 132:180-211. | Article | PubMed

13. Lansky EP and St Louis EK. Transcendental meditation: a double-edged sword in epilepsy? Epilepsy Behav. 2006; 9:394-400. I Article I PubMed

14. Manocha R. Why meditation? Aust Fam Physician. 2000; 29:1135-1138. I PubMed

15. Kaushik RM, Kaushik R, Mahajan SK and Rajesh V. Effects of mental relaxation and slow breathing in essential hypertension. Complement Ther Med. 2006; 14:120-126. I Article I PubMed 
16. Joshi DV, Dahake PA and Suthar PA. Adverse Effects Associated with the Use of Antihypertensive Drugs: An Overview. International Journal of PharmTech Research. 2010; 2:10-13. I Pdf

17. Dalal K. and Das R. Noninvasive characterization of foot reflexology areas by swept source-optical coherence tomography in patients with low back pain. Evidence-Based Complementary and Alternative Medicine. 2013; 213; 1-11. I Article

18. Hughes CM, Krirsnakriengkrai S, Kumar S and McDonough SM. The effect of reflexology on the autonomic nervous system in healthy adults: a feasibility study. Altern Ther Health Med. 2011; 17:32-37. | PubMed

19. Jones S. Simply Reflexology. $1^{\text {st }}$ ed. Sterling Publishing Company Inc. New York. 2009; 9-11.

20. Jevning $\mathrm{R}$, Wallace RK and Beidebach $\mathrm{M}$. The physiology of meditation: a review. A wakeful hypometabolic integrated response. Neurosci Biobehav Rev. 1992; 16:415-424. | Article | PubMed

21. Park HS and Cho GY. [Effects of foot reflexology on essential hypertension patients]. Taehan Kanho Hakhoe Chi. 2004; 34:739-750. | Article I PubMed

22. Terwee CB, Bot SD, de Boer MR, van der Windt DA, Knol DL, Dekker J, Bouter LM and de Vet HC. Quality criteria were proposed for measurement properties of health status questionnaires. J Clin Epidemiol. 2007; 60:34-42. | Article | PubMed

23. Harrison-Bernard LM and Raij L. Postmenopausal hypertension. Curr Hypertens Rep. 2000; 2:202-207. I PubMed

24. Kaur J, Kaur S and Bhardwaj N. Effect of 'foot massage and reflexology' on physiological parameters of critically ill patients. Nursing and Midwifery. Research Journal. 2012; 8:223-233.

25. Rankin-Box D. The Nurse's Handbook of Complementary Therapies. 2nd ed. Bailliere Tindall. UK. USA. 2001; 125-135.

26. Benson H. Relaxaion technique. A practical hand book for the health care professional. Churchil living stone. Edinburgh. 1995; 3-11.

27. Sivasankaran S, Pollard-Quintner S, Sachdeva R, Pugeda J, Hoq SM and Zarich SW. The effect of a six-week program of yoga and meditation on brachial artery reactivity: do psychosocial interventions affect vascular tone? Clin Cardiol. 2006; 29:393-398. | Article | PubMed

28. Schneider RH, Grim CE, Rainforth MV, Kotchen T, Nidich SI, Gaylord-King C, Salerno JW, Kotchen JM and Alexander CN. Stress reduction in the secondary prevention of cardiovascular disease: randomized, controlled trial of transcendental meditation and health education in Blacks. Circ Cardiovasc Qual Outcomes. 2012; 5:750-758. | Article | PubMed

29. Nidich SI, Rainforth MV, Haaga DA, Hagelin J, Salerno JW, Travis F, Tanner M, Gaylord-King C, Grosswald S and Schneider RH. A randomized controlled trial on effects of the Transcendental Meditation program on blood pressure, psychological distress, and coping in young adults. Am J Hypertens. 2009; 22:1326-1331. | Article | PubMed Abstract | PubMed FullText

30. Joseph CN, Porta C, Casucci G, Casiraghi N, Maffeis M, Rossi M and Bernardi L. Slow breathing improves arterial baroreflex sensitivity and decreases blood pressure in essential hypertension. Hypertension. 2005; 46:714-718. | Article | PubMed

31. Cramer H, Haller H, Lauche R, Steckhan N, Michalsen A and Dobos G. A systematic review and meta-analysis of yoga for hypertension. Am J Hypertens. 2014; 27:1146-1151. | Article | PubMed

32. Parati $G$ and Steptoe A. Stress reduction and blood pressure control in hypertension: a role for transcendental meditation? J Hypertens. 2004 22:2057-2060. | Article | PubMed

\section{Citation:}

El-Refaye GE and Elsisi HFEM. The blood pressure response to foot reflexology adjunct to transcendental meditation training on postmenopausal hypertension. Phys Ther Rehabil. 2017; 4:4.

http://dx.doi.org/10.7243/2055-2386-4-4 